\title{
What Microwave Astronomical Spectroscopy can tell you about the Carriers of the DIBs
}

\author{
H. Liszt ${ }^{1}$, R. Lucas $^{2}$, J. Pety ${ }^{3,4}$ \& M. Gerin ${ }^{5,4}$ \\ ${ }^{1}$ Notional Radio Astronomy Observatory, 520 Edgemont Road, Charlottesville, VA USA 22903 \\ ${ }^{2}$ Institut de Plantologie et d.Astrophysique de Grenoble (UMR 5274) \\ BP 53 F-38041 Grenoble Cedex 9, France \\ ${ }^{3}$ Institut de Radioastronomie Millimétrique, \\ 300 Rue de la Piscine F-38406 Saint Martin d'Hères, France \\ ${ }^{4}$ Obs. de Paris, 61 av. de l'Observatoire, 75014, Paris, France \\ ${ }^{5}$ LERMA/LRA, Ecole Normale Suprieure, 24 rue Lhomond, 75005 Paris, France
}

\begin{abstract}
Astronomical microwave spectroscopy has greatly broadened the inventory of identifiable chemical species in diffuse molecular gas and is an increasingly effective way to measure the abundances of polar molecules that may be candidate diffuse interstellar band carriers. Here we review some recent developments that hold new promise for chemical abundance determinations. We summarize and categorize the molecular inventory that has accrued in the past twenty years from microwave observations of diffuse clouds and we present summary tables of the molecular abundances within various chemical families in both dark and diffuse molecular gas.
\end{abstract}

Keywords. astrochemistry; ISM: molecules; ISM: lines and bands; techniques: spectroscopic

\section{Introduction}

It is a paradox that the uv/optical spectrum is so rich in atomic lines and diffuse interstellar bands (DIBs) and so empty of the identifiable molecular spectra that might finger the DIB carriers. $\mathrm{CH}, \mathrm{CH}^{+}$and $\mathrm{CN}$ were identified in optical spectra when study of the interstellar medium was relatively new and it was expected that the carriers of the DIBs would soon also be identified. But the known molecular inventory grew only very slowly in optical/uv spectra with the detection of $\mathrm{H}_{2}, \mathrm{CO}, \mathrm{C}_{2}, \mathrm{C}_{3}$ and $\mathrm{NH}$ (Snow \& McCall 2006). The optical spectrum alone provides little guidance and the DIB carriers remain unidentified.

By contrast, the microwave spectrum proved to be very fertile ground for astrochemistry, with the detection of more than 150 interstellar species since 1963 when OH was discovered. These are mostly studied in emission toward "dark," "giant," "molecular," and "infrared dark" clouds having visual extinctions $\mathrm{A}_{\mathrm{V}}>5$ mag. but substantial progress has also been made in detecting polyatomic molecules in regions with $A_{V}<1$ mag, in fact almost at the point where $\mathrm{H}_{2}$ itself "turns on" at reddening $\mathrm{E}_{\mathrm{B}-\mathrm{V}} \approx 0.08$ mag or $\mathrm{A}_{\mathrm{V}} \approx 0.25 \mathrm{mag}$ (Savage et al. 1977). Doing so only requires observing in absorption at radio wavelengths, as we discuss here.

Here we make the case for the usefulness of radioastronomical microwave spectroscopy to the quest for the carriers of the DIBs. This rests on establishing several elements. The spectroscopy must be capable of observing relevant species and setting significant limits on their abundances. Morever, it must be capable of observing those species in interstellar environments that are relevant to the DIBs. The latter point is perhaps the hardest to establish because stars are not suitable background sources at radio wavelengths and the 
same sightlines are not observed in both optical and microwave absorption (a possible future exception is discussed below). Largely on this account the optical/uv observing community has been very slow to acknowledge that diffuse clouds are actually observable in the microwave domain. However, the recent microwave determination (Liszt et al. 2012 ) of the abundance of the DIB carrier candidate $l-\mathrm{C}_{3} \mathrm{H}_{2}$ (Maier et al. $2011 \mathrm{~b}$ ) seems to have had some impact and may be seen as an initial step in cross-fertilization between the optical and microwave domains.

The organization of this work is as follows. Section 2 provides an exceedingly brief overview of the sensitivity to molecular abundance that is available in the microwave domain and an equally brief description ot the kinds of transitions and molecular species that are accessible. It includes some specific examples of recent detections of new species in diffuse gas as a way of illustrating instrumental capabilities. The systematics of the chemistry are shown in Section 3 and the overall microwave molecular inventory is presented in Section 4 along with summary tables of relative abundances in dark and diffuse gas. Section 5 provide a practical summary of the overall relevance of this work to the quest for the identities of the DIB carriers.

\section{Considerations of observability and sensitivity}

\subsection{Sensitivity to column density}

There are two essential aspects of calculating the strength of an interstellar microwave absorption line. First, as with optical spectroscopy, are the particulars of the spectroscopic data for that particular transition, and for known interstellar species these can generally be found in radioastronomical spectroscopic databases $\uparrow$. Second is the issue of rotational and fine-structure excitation within the ground vibrational state molecular energy level structure and this is somewhat different at radio wavelengths; substantial population exists in equilibrium in both the upper and lower levels of the transition and the molecular population is spread over more energy levels (and perhaps many more) than are actually observed.

For a transition at frequency $\nu$, between lower and upper levels $\mathrm{j}$ and $\mathrm{k}$ having statistical weights $\mathrm{g}_{j}$ and $\mathrm{g}_{k}$ and an Einstein A-coefficient $\mathrm{A}_{k j}$, the column density of molecules $\mathrm{N}_{j}$ in the lower level $\mathrm{j}$ and the integrated optical depth (in cgs velocity units) are related as

$$
\int \tau d v=\left(c^{3} /\left(8 \pi \nu^{3}\right)\right)\left(g_{k} / g_{j}\right) A_{k j}\left(1-\exp \left(-h \nu / k T_{\text {exc }}\right)\right) N_{j}
$$

In this expression $T_{\text {exc }}$ is the excitation temperature of the transition, $\mathrm{N}_{k} / \mathrm{N}_{j}=$ $\left(\mathrm{g}_{k} / \mathrm{g}_{j} \exp \left(-h \nu / k T_{\text {exc }}\right)\right.$. Because $h \nu / k T_{\mathrm{CMB}}$ is not large $\left(h \nu / k T_{\mathrm{CMB}}=1\right.$ for $\nu=57$ $\mathrm{GHz}$ ) the correction for stimulated emission is usually important, appreciably lowering the optical depth and overall sensitivity. Beyond this the molecular population is spread over various energy levels even when there is no appreciable excitation above the cosmic microwave background. To derive the total column density $\mathrm{N}$ from a single measurement, the partition function (sum of population over all levels) must be calculated to evaluate the ratio $\mathrm{Q}=\mathrm{N} / \mathrm{N}_{l}$. The observability to a particular species at a given radiotelescope can be optimized by choosing a transition that minimizes this ratio.

In diffuse gas the ambient density is relatively small and the distribution of population over the rotational energy ladder is well-characterized by taking $T_{\text {exc }}=T_{\mathrm{CMB}}$; this is verified by observing emission from species whose optical depths are known in absorption (Lucas \& Liszt 1996; Liszt 2012).

$\dagger$ www.splatalogue.net, www.astro.uni-koeln.de/cdms, www.spec.jpl.nasa.gov 

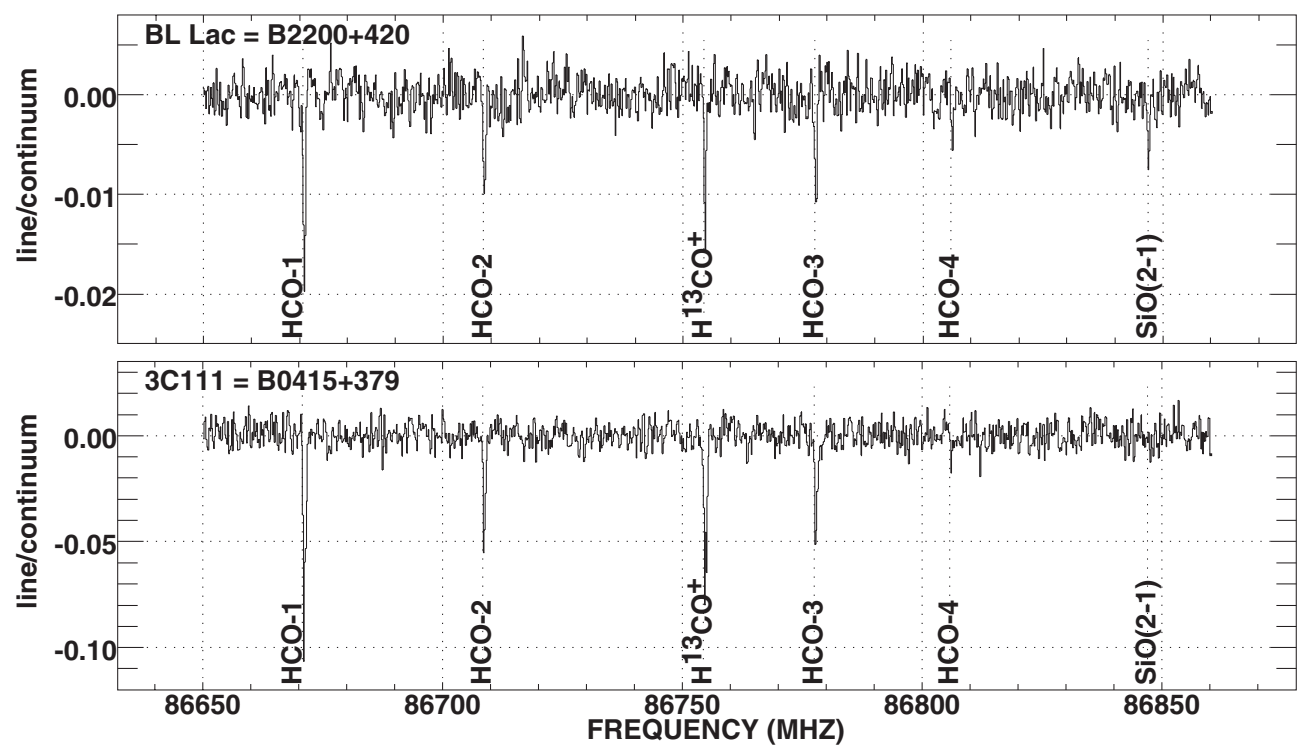

Figure 1. MM-wave galactic absorption spectra toward two blazars, excerpted from a 85-115 $\mathrm{GHz}$ spectral sweep using the EMIR receiver at the IRAM $30 \mathrm{~m}$ telescope. The spectral resolution is $195 \mathrm{kHz}$.

\subsection{Observability of various species}

Heavier diatomic and smaller linear molecules (ie not $\mathrm{OH}, \mathrm{NH}_{3}, \mathrm{H}_{2} \mathrm{CO}$ ) are generally observed in pure rotational transitions at mm-wave frequencies and have little population in rotational levels above $\mathrm{J}=2$. For a commonly observed linear species like $\mathrm{HCO}^{+}$with a comparatively large permanent dipole moment 3.89 Debye and a $\mathrm{J}=1-0$ transition at $89.188 \mathrm{GHz}$, an integrated optical depth of $1 \mathrm{~km} \mathrm{~s}^{-1}$ corresponds to $\mathrm{N}\left(\mathrm{HCO}^{+}\right)=1.12 \times$ $10^{12} \mathrm{~cm}^{-2}$ when $T_{\text {exc }}=T_{\mathrm{CMB}}$. Column densities $\mathrm{N}\left(\mathrm{HCO}^{+}\right) 10^{10} \mathrm{~cm}^{-2}$ are easily accessible corresponding to molecular hydrogen column densities as small as $\mathrm{N}\left(\mathrm{H}_{2}\right)=3 \times 10^{18} \mathrm{~cm}^{-2}$. As seen in Figure 1, the ${ }^{13} \mathrm{C}$-substituted variant of $\mathrm{HCO}^{+}$is easily detected toward $\mathrm{BL}$ Lac at $\mathrm{A}_{\mathrm{V}}=1 \mathrm{mag}$.

Heavier species have smaller rotational constants and transitions that lie lower in frequency, with population spread over more levels. In terms of the partition function, $\mathrm{C}_{4} \mathrm{H}$ is optimally observed in the $\mathrm{N}=2-1$ transitions near $19.015 \mathrm{GHz}$, and an integrated optical depth of $1 \mathrm{~km} \mathrm{~s}^{-1}$ corresponds only to $\mathrm{N}\left(\mathrm{C}_{4} \mathrm{H}\right)=7-10 \times 10^{14} \mathrm{~cm}^{-2}$ if the permanent dipole moment (which is somewhat uncertain) is as small as 0.8 Debye. By contrast, the $\mathrm{C}_{4} \mathrm{H}^{-}$anion with transitions at $18.6 \mathrm{GHz}$ has a dipole moment of 6.2 Debye and a column density sensitivity nearly two orders of magnitude better (Liszt et al. 2012).

Transitions are also observable that are not purely rotational. Four hyperfine transitions of $\mathrm{OH}$ are observed between 1612 and $1712 \mathrm{MHz}$ and an integrated optical depth of $1 \mathrm{~km} \mathrm{~s}^{-1}$ in the strongest of these at $1667 \mathrm{MHz}$ corresponds to $\mathrm{N}(\mathrm{OH}) \approx 3 \times 10^{14} \mathrm{~cm}^{-2}$; however $\mathrm{OH}$ is observed with very large instruments and column densities well below $\mathrm{N}(\mathrm{OH})=10^{13} \mathrm{~cm}^{-2}$ are easily accessible (Liszt \& Lucas 1996). As an asymmetric rotor, $\mathrm{H}_{2} \mathrm{CO}$ is observed in rotational transitions at mm-wavelengths and in K-doubling transitions at 4.830 and $14.480 \mathrm{GHz}$ (Liszt et al. 2006). $\mathrm{NH}_{3}$ is seen at $23.7 \mathrm{GHz}$ because of inversion doubling of its ground-state pyramidal structure (ibid). The pure rotational transitions of $\mathrm{OH}$ and $\mathrm{NH}_{3}$ are observable in diffuse gas in the sub-mm domain (above $300 \mathrm{GHz}$ ). Column densities for these three species are shown in Figure 5. 
Each species therefore must be taken on its own terms in terms of both observability and sensitivity and no one radiotelescope is capable of observing the full panoply of interstellar species. However, nearly the entire microwave spectrum from $300 \mathrm{MHz}$ to $300 \mathrm{GHz}$, temporarily excepting 70 - $84 \mathrm{GHz}$ (for instrumental reasons) and some opaque atomospheric windows, is observable with large modern instruments.

Microwave radioastronomical spectra have always had relatively good velocity resolution but only recently has it become possible to observe with such high resolution over large fractional bandwidths. Figure 1 shows the recent initial detection of galactic HCO in absorption at $86.7 \mathrm{GHz}$ against the blazar $\mathrm{BL}$ Lac at $1, \mathrm{~b}=92.6^{\circ},-10.44^{\circ}$ with $\mathrm{E}_{\mathrm{B}-\mathrm{V}}=$ $0.33 \mathrm{mag}$ and toward $3 \mathrm{C} 111$ at $1, \mathrm{~b}=161.7^{\circ},-8.8^{\circ}$ with $\mathrm{E}_{\mathrm{B}-\mathrm{V}}=1.65 \mathrm{mag}$; all reddenings quoted here are from Schlegel et al. (1998). The absorbing gas seen in the 4 hyperfine components of the $1_{01}-0_{00}$ transition of $\mathrm{HCO}$ and in the $\mathrm{H}^{13} \mathrm{CO}^{+} \mathrm{J}=1-0$ and $\mathrm{SiO} \mathrm{J}=$ 2-1 transitions is at $\mathrm{v}=-1 \mathrm{~km} \mathrm{~s}^{-1}$ in both directions in the LSRK velocity rest frame and lies within a few hundred pc of the Sun at these moderate galactic latitudes.

These spectra were made by beam-switching against adjacent sky at the IRAM $30 \mathrm{~m}$ telescope using the EMIR receiver that simultaneously observes over two $8 \mathrm{GHz}$-wide sidebands with $195 \mathrm{kHz}$ spectral resolution, corresponding to $0.6 \mathrm{~km} \mathrm{~s}^{-1}$ at $100 \mathrm{GHz}$. BL Lac was flaring at $15 \mathrm{Jy}$ and 3C111 was anomalously weak at $3 \mathrm{Jy}$ during these observations, which represent a very small portion of the $32 \mathrm{GHz}$-wide spectrum constructed with several LO settings during some 25 hours observing toward each source. Toward $\mathrm{BL}$ Lac we derive $\mathrm{N}(\mathrm{HCO})=8.5 \times 10^{11} \mathrm{~cm}^{-2}, \mathrm{~N}\left(\mathrm{H}^{13} \mathrm{CO}^{+}\right)=4.4 \times 10^{10} \mathrm{~cm}^{-2}$ and $\mathrm{N}(\mathrm{SiO})=4.8 \times 10^{10} \mathrm{~cm}^{-2}$. The column densities of $\mathrm{HCO}$ and $\mathrm{HCO}^{+}$per unit reddening are very nearly the same in both directions but notice that $\mathrm{SiO}$ is weaker along the translucent sightline to $3 \mathrm{C} 111$. $\mathrm{SiO}$ was previously observed along most of the sightlines discussed here Lucas \& Liszt (2000b) but the detection toward BL Lac is new.

The observing bandwidths for high-resolution spectroscopy at the VLA are improving rapidly as a new spectrometer is commissioned. Figure 2 from Liszt et al. (2012) shows absorption from the ortho-cyclic and para-linear versions of $\mathrm{C}_{3} \mathrm{H}_{2}$ made in 4 hours (total) observing using the VLA at $18.5 \mathrm{GHz}$ toward four blazars including those shown in Figure 1, but also toward $\mathrm{B} 2251+158=3 \mathrm{C} 454.3$ at $1, \mathrm{~b}=86.1^{\circ},-38.2^{\circ}$ with $\mathrm{E}_{\mathrm{B}-\mathrm{V}}$ $=0.11$ mag. $\mathrm{C}_{3} \mathrm{H}_{2}$ is ubiquitous in diffuse molecular gas and $\left.<\mathrm{N}\left(c-\mathrm{C}_{3} \mathrm{H}_{2}\right) / \mathrm{E}_{\mathrm{B}-\mathrm{V}}\right\rangle=$ $3.3 \pm 0.11 \times 10^{12} / \mathrm{mag}$ averaged over the four sightlines. However $\mathrm{N}\left(c-\mathrm{C}_{3} \mathrm{H}_{2}\right) / \mathrm{N}\left(l-\mathrm{C}_{3} \mathrm{H}_{2}\right)$ $\approx 17$ and $\left.\left\langle\mathrm{N}\left(l-\mathrm{C}_{3} \mathrm{H}_{2}\right)\right) / \mathrm{E}_{\mathrm{B}-\mathrm{V}}\right\rangle=2 \pm 1 \times 10^{11} \mathrm{~cm}^{-2} / \mathrm{mag}$. This is much smaller than what would be needed for $l-\mathrm{C}_{3} \mathrm{H}_{2}$ to carry the the $5069 \AA$ DIB with which it could be associated on the basis of spectroscopic coincidences; Maier et al. (2011a) quote $\mathrm{N}\left(l-\mathrm{C}_{3} \mathrm{H}_{2}\right)$ / $\mathrm{E}_{\mathrm{B}-\mathrm{V}}=5 \times 10^{14} \mathrm{~cm}^{-2} / \mathrm{mag}$.

\subsection{Some stuff we ignored or slighted}

The narrow focus of this work prevented discussion of the extensive molecular inventory that has recently been discovered and studied in the sub-mm regime above $300 \mathrm{GHz}$ with the Herschel satellite under the PRISMAS Project $-\mathrm{CH}^{+}$and $\mathrm{SH}^{+} ; \mathrm{OH}^{+}, \mathrm{OH}_{2}{ }^{+}$ and $\mathrm{OH}_{3}{ }^{+}$; $\mathrm{OH}$ and $\mathrm{H}_{2} \mathrm{O} ; \mathrm{NH}, \mathrm{NH}_{2}$ and $\mathrm{NH}_{3}$; and $\mathrm{HF}$, among others. Some of these, for instance $\mathrm{OH}^{+}$(Indriolo et al. 2012), are preferentially found in regions of very small molecular fraction that may have special relevance to study of the DIBs.

The spectroscopic summary earlier in this Section can be supplemented by recent discussions of interstellar molecules and chemistry, for instance Tielens (2010) and Yamada \& Winnewisser (2011). A standard reference to observing techniques in the microwave regime is found in Wilson et al. (2009). 

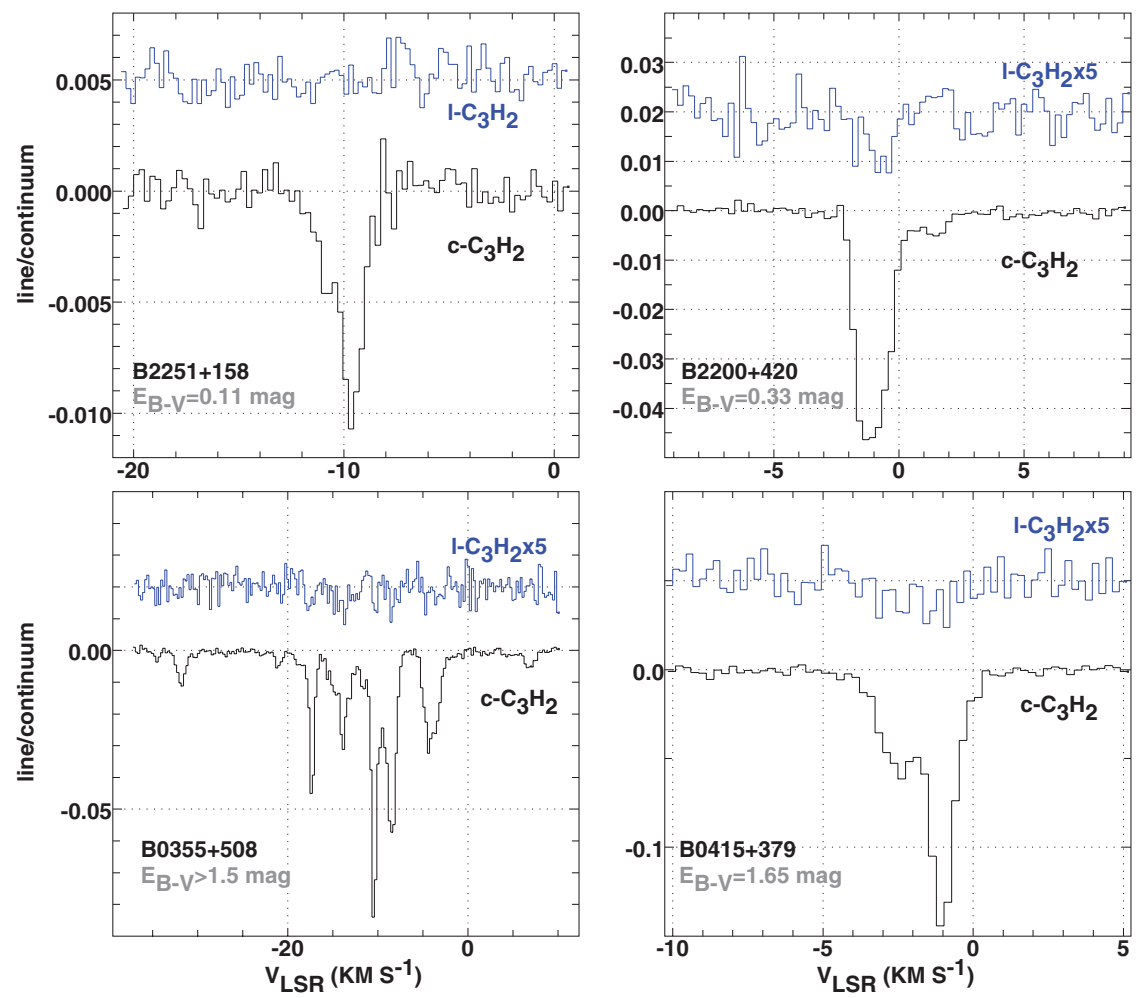

Figure 2. $19 \mathrm{GHz}$ VLA absorption spectra of linear-para and ortho-cyclic $\mathrm{C}_{3} \mathrm{H}_{2}$ toward four blazars, from Liszt et al. (2012)
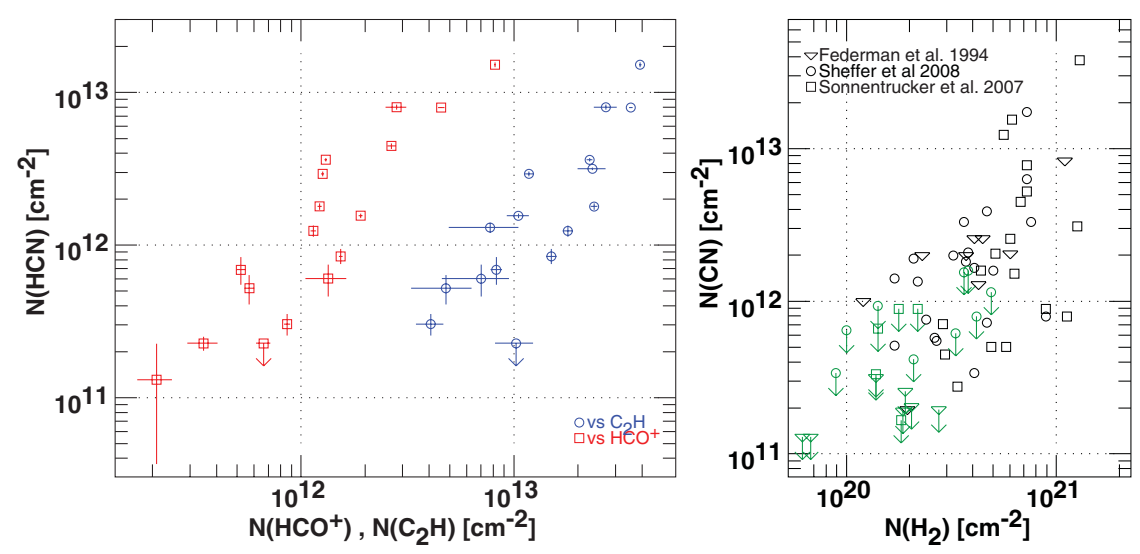

Figure 3. Left: HCN column density variations determined at radio frequencies with respect to $\mathrm{HCO}^{+}$and $\mathrm{C}_{2} \mathrm{H}$ (Liszt \& Lucas 2001) . Right: Variation of $\mathrm{N}(\mathrm{CN})$ with $\mathrm{N}\left(\mathrm{H}_{2}\right)$ from optical/uv spectra (Federman et al. 1994; Sheffer et al. 2008; Sonnentrucker et al. 2007).

\section{Systematics}

One general result of molecular spectroscopy is the presence of a small core group of ubiquitously species having stable (nearly-fixed) abundances with respect to each other and $\mathrm{H}_{2}$. The group includes $\mathrm{OH}$ and $\mathrm{HCO}^{+}$(Lucas \& Liszt 1996; Liszt \& Lucas 1996; Liszt et al. 2010) along with the hydrocarbons $\mathrm{CH}, \mathrm{C}_{2} \mathrm{H}$ and $\mathrm{c}^{-} \mathrm{C}_{3} \mathrm{H}_{2}$ (Lucas \& Liszt 2000a; 
Table 1. Molecular inventory from microwave spectroscopy

\begin{tabular}{|c|c|c|c|}
\hline Family | & Detected & Search in progress & Upper limit \\
\hline $\mathrm{CH}$ & 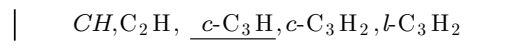 & $l-\mathrm{C}_{3} \mathrm{H}$ & $\mathrm{C}_{4} \mathrm{H}, \mathrm{C}_{4} \mathrm{H}^{-}$ \\
\hline $\mathrm{OH}$ & $\mathrm{OH}, \mathrm{H}_{2} \mathrm{O}, \mathrm{CO}, \mathrm{HCO}^{+}, \mathrm{HOC}^{+}, \underline{\mathrm{HCO}}, \mathrm{H}_{2} \mathrm{CO}$ & $\mathrm{H}_{2} \mathrm{COH}^{+}$ & $\mathrm{CH}_{3} \mathrm{OH}$ \\
\hline $\mathrm{CN}$ & $C N, \mathrm{HCN}, \mathrm{HNC}, \mathrm{NH}_{3}$ & \multicolumn{2}{|c|}{$\left|\mathrm{HC}_{3} \mathrm{~N}, \mathrm{CH}_{2} \mathrm{CN}, \mathrm{CH}_{3} \mathrm{CN}, \mathrm{CH}_{3} \mathrm{NC}, \mathrm{HNCO}\right| \mathrm{HC}_{5} \mathrm{~N}, \mathrm{~N}_{2} \mathrm{H}^{+}$} \\
\hline CS & $\mathrm{CS}, \mathrm{SO}, \mathrm{H}_{2} \mathrm{~S}, \mathrm{HCS}^{+}$ & OCS & $\mathrm{SO}_{2}, \mathrm{H}_{2} \mathrm{CS}$ \\
\hline $\mathrm{SiO}$ & $\mathrm{SiO}$ & | & $\mathrm{SiS}$ \\
\hline $\mathrm{CF}^{+}$ & $\underline{\mathrm{CF}^{+}}$ & | & | \\
\hline
\end{tabular}

Notes:

$\underline{\text { species }}=$ new detection (unpublished); species $=$ also seen in optical $/$ uv

Gerin et al. 2011). Less-abundant species such as $l-\mathrm{C}_{3} \mathrm{H}_{2}$ have not been traced in sufficient detail to be included. The fixed ratios $\mathrm{X}(\mathrm{CH})=\mathrm{N}(\mathrm{CH}) / \mathrm{N}\left(\mathrm{H}_{2}\right)=3.5 \times 10^{-8}$ and $\mathrm{X}(\mathrm{OH})$ $=\mathrm{N}(\mathrm{OH}) / \mathrm{N}\left(\mathrm{H}_{2}\right)=1 \times 10^{-7}$ are directly measured at optical/uv wavelengths (Weselak et al. 2010). In turn, $\mathrm{OH}$ and $\mathrm{HCO}^{+}$have a very nearly fixed ratio $\mathrm{N}(\mathrm{OH}) / \mathrm{N}\left(\mathrm{HCO}^{+}\right)=$ $30-50$ at radio wavelengths, providing one of a few direct ties between the abundances of species seen in the optical and radio regimes. Knowing that $\mathrm{X}\left(\mathrm{HCO}^{+}\right)=2-3 \times 10^{-9}$ provides a convenient scale with which to measure the abundances of other species seen in the radio regime.

Another tie-in between the optical and radio regimes is provided by $113 \mathrm{GHz}$ measurements of $\mathrm{CN}$, which is always accompanied by $\mathrm{HCN}$ and $\mathrm{HNC}$ in the ratio $\mathrm{CN}: \mathrm{HCN}: \mathrm{HNC}=6.8: 1: 0.21$ (Liszt \& Lucas 2001). The large HCN/HNC ratio is typical of warmer molecular gas (ie 30-50 K) as opposed to a dark cloud like TMC-1 at $10 \mathrm{~K}$ where all three species have comparable abundances (see the table in Figure 5). Figure 3 uses the $\mathrm{CN}$-family abundances to illustrate the relative stability of the core group abundances of $\mathrm{HCO}^{+}$and $\mathrm{C}_{2} \mathrm{H}$ and the rapid increase in the abundances of species outside the core group at $\mathrm{N}\left(\mathrm{HCO}^{+}\right) \approx 10^{12} \mathrm{~cm}^{-2}$, corresponding to $\mathrm{N}\left(\mathrm{H}_{2}\right) \approx 3 \times 10^{20} \mathrm{~cm}^{-2}$. Shown at left is the variation of $\mathrm{N}(\mathrm{HCN})$ with respect to $\mathrm{N}\left(\mathrm{HCO}^{+}\right)$and $\mathrm{N}\left(\mathrm{C}_{2} \mathrm{H}\right)$ and at right the analogous behaviour of $\mathrm{CN}$ with respect to $\mathrm{H}_{2}$. The abundance of $\mathrm{HCN}$ increases by about a factor 100 over relatively small ranges in $\mathrm{N}\left(\mathrm{HCO}^{+}\right)$or $\mathrm{N}\left(\mathrm{C}_{2} \mathrm{H}\right)$ and $\mathrm{CN}$ is not detected reliably when $\mathrm{N}\left(\mathrm{H}_{2}\right)<2-3 \times 10^{20} \mathrm{~cm}^{-2}$.

Figure 4 ties the core group and $\mathrm{CN}$-family to the remainder of the observable molecular inventory using the many absorbing features found along the line of sight to B0355+508 (also shown in Figures 2 and 3). Although this line of sight at galactic latitude $\mathrm{b}=-1.6^{\circ}$ is optically very opaque when viewed through the galactic disk, the five most strongly $\mathrm{H}_{2}$-bearing clouds are individually diffuse, all with $\mathrm{N}\left(\mathrm{HCO}^{+}\right) \approx 1.4 \times 10^{12} \mathrm{~cm}^{-2}$ or $\mathrm{N}\left(\mathrm{H}_{2}\right) \approx 4 \times 10^{20} \mathrm{~cm}^{-2}$, which is about half that seen toward BL Lac where $\mathrm{A}_{\mathrm{V}}=1$ mag. Although all of the five strong kinematic absorption components have about equal molecular content only the two at $-11 \mathrm{~km} \mathrm{~s}^{-1}$ and $-17 \mathrm{~km} \mathrm{~s}^{-1}$ are strong in $\mathrm{H}_{2} \mathrm{CO}, \mathrm{CS}$, $\mathrm{H}_{2} \mathrm{~S}, \mathrm{HCN}$ and $\mathrm{NH}_{3}$. The component at $-8.5 \mathrm{~km} \mathrm{~s}^{-1}$ has weak absorption in $\mathrm{HCN}$ and perhaps in $\mathrm{H}_{2} \mathrm{CO}$. The $\mathrm{NH}_{3}$ spectrum at top is complicated by hyperfine structure and the component at $-4 \mathrm{~km} \mathrm{~s}^{-1}$ is actually missing.

Figure 4 shows that species outside the core group appear or disappear together. Carbon monoxide is an exception because it is seen almost as ubiquitously as the core group species but its abundance is more variable (Liszt \& Lucas 1998). Confusingly, three of the strong absorption features are equally strong in $\mathrm{CO}$ emission, including those two that show stronger HNC, etc, but $\mathrm{CO}$ emission is also strong in the feature at -8.5 


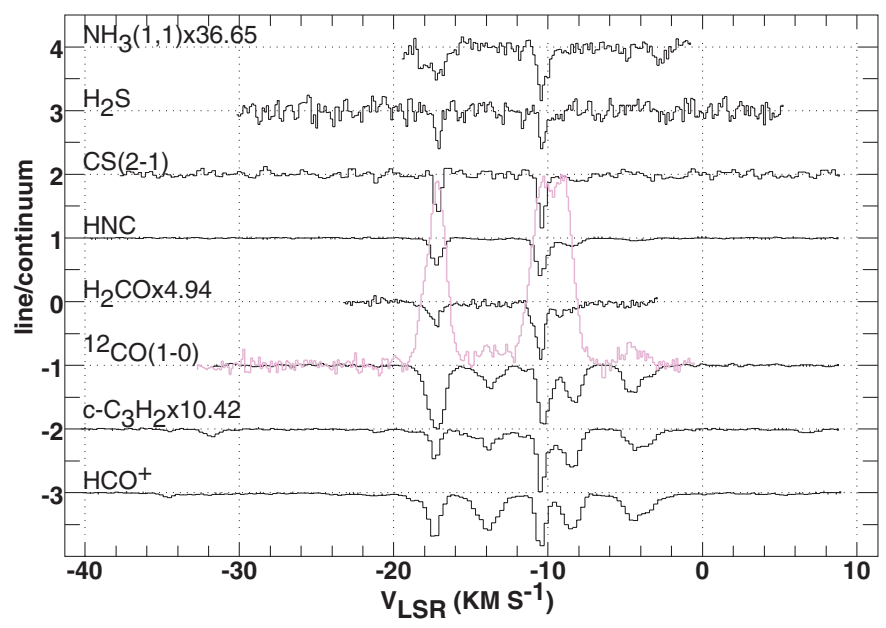

Figure 4. Absorption spectra toward B0355+508 (see also Figure 2), vertically offset and scaled as noted to fill more of the display. Shown as a faint cyan overlay just above the CO absorption spectrum is the CO $\mathrm{J}=1-0$ emission profile seen in this direction at $1^{\prime}$ spatial resolution; the peak brightness is $3 \mathrm{~K}$.

\begin{tabular}{|c|c|c|c|c|c|c|c|c|}
\hline Source & $\underset{\mathrm{mag}}{\mathrm{A}_{\mathrm{v}}}$ & $\begin{array}{c}\mathrm{OH} / \mathrm{A}_{\mathrm{V}} \\
\mathrm{cm}^{-2} / \mathrm{mag}\end{array}$ & $\mathbf{X}(\mathrm{OH})$ & $\begin{array}{c}\mathbf{X}\left(\mathrm{HCO}^{+}\right) \\
/ \mathbf{X}(\mathrm{OH})\end{array}$ & $\begin{array}{c}\mathbf{X}\left(\mathrm{HOC}^{+}\right) \\
/ \mathbf{X}(\mathrm{OH})\end{array}$ & $\begin{array}{c}\mathbf{X}(\mathrm{HCO}) \\
/ \mathbf{X}(\mathrm{OH})\end{array}$ & $\begin{array}{c}\mathbf{X}\left(\mathrm{H}_{2} \mathrm{CO}\right) \\
/ \mathbf{X}(\mathrm{OH})\end{array}$ & $\begin{array}{c}\mathrm{X}\left(\mathrm{CH}_{3} \mathrm{OH}\right) \\
/ \mathrm{X}(\mathrm{OH})\end{array}$ \\
\hline TMC-1 & 10 & $2 \times 10^{14}$ & $2 \times 10^{-7}$ & $1 / 30$ & $?$ & $1 / 1200$ & $1 / 1$ & $1 / 100$ \\
\hline BL Lac & 1 & $2 \times 10^{14}$ & $1 \times 10^{-7}$ & $1 / 30$ & $1 / 2500$ & $1 / 120$ & $1 / 16$ & $<1 / 10$ \\
\hline Source & $\begin{array}{c}\mathbf{A}_{\mathbf{v}} \\
\mathrm{mag}\end{array}$ & $\begin{array}{l}\mathrm{C}_{2} \mathrm{H} / \mathrm{A}_{\mathrm{V}} \\
\mathrm{cm}^{-2} / \mathrm{mag}\end{array}$ & $\mathbf{X}\left(\mathrm{C}_{2} \mathrm{H}\right)$ & $\begin{array}{c}\mathbf{X}\left(c-\mathrm{C}_{3} \mathrm{H}\right) \\
\mathbf{X}\left(\mathrm{C}_{2} \mathrm{H}\right)\end{array}$ & $\begin{array}{c}\mathrm{X}\left(2-\mathrm{C}_{3} \mathrm{H}\right) \\
\mathbf{X}\left(\mathrm{C}_{2} \mathrm{H}\right)\end{array}$ & $\begin{array}{c}\mathbf{X}\left(c-\mathrm{C}_{3} \mathrm{H}_{2}\right) \\
/ \mathbf{X}\left(\mathrm{C}_{2} \mathrm{H}\right)\end{array}$ & $\begin{array}{c}\mathbf{X}\left(2-\mathrm{C}_{3} \mathrm{H}_{2}\right) \\
/ \mathbf{X}\left(\mathrm{C}_{2} \mathrm{H}\right)\end{array}$ & $\begin{array}{l}\mathbf{X}\left(\mathrm{C}_{4} \mathrm{H}\right) \\
\mathbf{X}\left(\mathrm{C}_{2} \mathrm{H}\right)\end{array}$ \\
\hline TMC-1 & 10 & $7 \times 10^{13}$ & $7 \times 10^{-8}$ & $1 / 115$ & $1 / 140$ & $1 / 7$ & $1 / 200$ & $1 / 3.5$ \\
\hline BL Lac & 1 & $3 \times 10^{13}$ & $3 \times 10^{-8}$ & $1 / 200$ & $?$ & $1 / 20$ & $1 / 350$ & $<1 / 10$ \\
\hline Source & $\begin{array}{l}A_{V} \\
\text { mag }\end{array}$ & $\begin{array}{c}\mathrm{CN} / \mathrm{A}_{\mathrm{V}} \\
\mathrm{cm}^{-2} / \mathrm{mag}\end{array}$ & $\mathrm{X}(\mathrm{CN})$ & $\begin{array}{c}\mathrm{X}(\mathrm{HCN}) \\
/ \mathbf{X}(\mathrm{CN})\end{array}$ & $\begin{array}{l}\mathbf{X}(\mathrm{HNC}) \\
\mathrm{X}(\mathrm{CN})\end{array}$ & $\begin{array}{l}\mathrm{X}\left(\mathrm{NH}_{3}\right) \\
/ \mathrm{X}(\mathrm{CN})\end{array}$ & $\begin{array}{c}\mathbf{X}\left(\mathrm{HC}_{3} \mathrm{~N}\right) \\
/ \mathrm{X}(\mathrm{CN})\end{array}$ & $\begin{array}{c}\mathrm{X}\left(\mathrm{HC}_{\mathrm{SN}}\right) \\
/ \mathrm{X}(\mathrm{CN})\end{array}$ \\
\hline TMC-1 & 10 & $3 \times 10^{13}$ & $3 \times 10^{-8}$ & $1 / 1.5$ & $1 / 1.5$ & $1 / 1.5$ & $1 / 5$ & $1 / 10$ \\
\hline BL Lac & 1 & $3 \times 10^{13}$ & $3 \times 10^{-8}$ & $1 / 7$ & $1 / 30$ & $1 / 9$ & $?$ & $<1 / 200$ \\
\hline Source & $\begin{array}{c}A_{V} \\
\text { mag }\end{array}$ & $\begin{array}{l}\mathrm{CS} / A_{V} \\
\mathrm{~cm}^{-2} / \text { mag }\end{array}$ & $\mathbf{X}(\mathrm{CS})$ & $\begin{array}{l}\mathbf{X}(\mathrm{SO}) \\
/ \mathbf{X}(\mathrm{CS})\end{array}$ & $\begin{array}{l}\mathbf{X}\left(\mathrm{H}_{2} \mathrm{~S}\right) \\
/ \mathrm{X}(\mathrm{CS})\end{array}$ & & & \\
\hline TMC-1 & 10 & $1 \times 10^{13}$ & $1 \times 10^{-8}$ & $1 / 2$ & $<1 / 20$ & & & \\
\hline BL Lac & 1 & $3 \times 10^{12}$ & $3 \times 10^{-9}$ & $3 / 2$ & $1 / 5$ & & & \\
\hline
\end{tabular}

Figure 5. Abundances toward TMC-1 (Ohishi et al. 1992; Turner et al. 2000; Smith et al. 2004) and BL Lac. Except for $\mathrm{CH}$, abundances relative to $\mathrm{H}_{2}$ toward $\mathrm{BL}$ Lac are relative to $\mathrm{HCO}^{+}$ with $\mathrm{X}\left(\mathrm{HCO}^{+}\right)=3 \times 10^{-9}$.

$\mathrm{kms}^{-1}$ having much weaker (but at least some?) HNC. The absorption components at $-13 \mathrm{~km} \mathrm{~s}^{-1}$ and $-4 \mathrm{~km} \mathrm{~s}^{-1}$ show obvious $\mathrm{CO}$ absorption and relatively little CO emission; they are examples of the so-called "CO-dark molecular gas," ie $\mathrm{H}_{2}$ that is not well-traced in $\mathrm{CO}$ emission. However, emission is absent only in the immediate vicinity of the continuum background target. Both features are strong in emission at other positions in the nearby sky field (Liszt \& Pety 2012) 


\subsection{Examples}

\section{The molecular inventory from microwave spectroscopy}

Table 1 summarizes the molecular inventory of diffuse clouds as known from microwave astronomical spectroscopy. Also included are species for which there are published upper limits, three species whose detection we discussed at IAU297 for the first time (underlined) and species that are currently being sought at the VLA. Species that are also observed in the optical/uv domain are underlined.

As discussed above, a single representative abundance can only be quoted for the few species in the small core group of $\mathrm{OH}, \mathrm{HCO}^{+}, \mathrm{CH}, \mathrm{C}_{2} \mathrm{H}$ and $c-\mathrm{C}_{3} \mathrm{H}_{2}$. Beyond this, the $\mathrm{CN}$-family, $\mathrm{CS}, \mathrm{H}_{2} \mathrm{CO}$ and $\mathrm{NH}_{3}$ have been shown to have widely-varying abundances and much smaller abundances at smaller $\mathrm{A}_{\mathrm{V}}, \mathrm{N}\left(\mathrm{HCO}^{+}\right.$) and $\mathrm{N}\left(\mathrm{H}_{2}\right)$ (Figures 3 and 4). Yet other species were observed too marginally or in too-limited a fashion to make statements about their systematics. There is some evidence that $l-\mathrm{C}_{3} \mathrm{H}$ is also in the core group.

The table in Figure 5 shows comparisons of molecular abundances across various chemical families at high and moderate extinction, the former represented by molecular emission measurements toward the cyanopolyyne peak in the dark cloud TMC-1 at $\mathrm{A}_{\mathrm{V}}=10 \mathrm{mag}$ (Ohishi et al. 1992; Smith et al. 2004) and the latter by our measurements toward BL Lac at $A_{V}=1$ mag. The abundances toward TMC-1 are subject to various uncertainties and only differences of a factor two or more between TMC-1 and BL Lac can be reliably said to be significant. The fractional abundances of the fiducial species toward BL Lac were set by taking their ratios with respect to $\mathrm{HCO}^{+}$, with $\mathrm{X}\left(\mathrm{HCO}^{+}\right)=3 \times 10^{-9}$.

In arranging this table the fiducial species were chosen as those that are the most abundant in TMC-1, ie $\mathrm{OH}, \mathrm{C}_{2} \mathrm{H}, \mathrm{CN}$ and $\mathrm{CS}$. Given the differences in physical conditions and chemistry in these two regimes it was hardly to be expected that the two sightlines would show any similarities at all but in fact the differences are mostly in the details. The fiducial species and the core group species have nearly the same relative abundances in both the dark and diffuse domains. We note that:

Hydroxyl. $\mathrm{OH}$ and $\mathrm{HCO}^{+}$have comparable relative abundances in both regimes. The diffuse gas has ten times more $\mathrm{HCO}$ and sixteen times less $\mathrm{H}_{2} \mathrm{CO}$. The fractional abundance of $\mathrm{CH}_{3} \mathrm{OH}$ in TMC-1 is well below the reach of the existing upper limit toward BL Lac. The actual degree of molecular complexity in the diffuse gas remains to be seen.

Hydrocarbons. $\mathrm{X}(\mathrm{CH}) / \mathrm{X}\left(\mathrm{C}_{2} \mathrm{H}\right) \approx 1 / 3$ toward TMC-1, making the hydrocarbons somewhat exceptional because the most abundant species is polyatomic. Within the range traced it is only marginally clear that the degree of molecular complexity is less in the diffuse gas. The abundance of $l-\mathrm{C}_{3} \mathrm{H}$ should be known soon. A better limit on $\mathrm{C}_{4} \mathrm{H}$ is needed.

Cyanogen. Toward TMC-1, CN, HCN, $\mathrm{HNC}$ and $\mathrm{NH}_{3}$ all have comparable abundances and that of $\mathrm{HC}_{5} \mathrm{~N}$ is ten times smaller. In the diffuse gas, $\mathrm{CN}$ is about ten times more abundant than $\mathrm{HCN}$ or $\mathrm{NH}_{3}$ and $\mathrm{X}(\mathrm{CN}) / \mathrm{X}\left(\mathrm{HC}_{5} \mathrm{~N}\right)=1 / 200$. The small $\mathrm{HNC} / \mathrm{HCN}$ ratio toward BL Lac is typical of warmer gas. The degree of molecular complexity is definitely lower toward BL Lac.

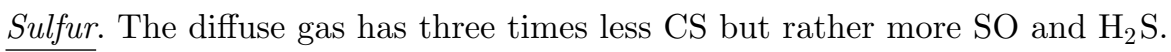

\section{What does all this mean for the carriers of the DIBs?}

If nothing else, microwave spectroscopy can directly provide measured interstellar abundances for specifically-targeted polar molecules that are proposed as DIB carrier candidates, extending far beyond the small set of species that is observable in optical 
spectroscopy. This was recently done for $l-\mathrm{C}_{3} \mathrm{H}_{2}$ and observations will soon be taken in a search for $\mathrm{CH}_{2} \mathrm{CN}$, whose cm-wave spectrum is well-known, in order to limit the abundance of the anion DIB-carrier candidate $\mathrm{CH}_{2} \mathrm{CN}^{-}$(Cordiner \& Sarre 2007) whose microwave spectrum is not yet published. Other examples will certainly follow.

Beyond this, Table 1 notes yet other molecular species, not necessarily putative DIBcarriers, that are being specifically targeted in contemporaneous VLA observations in order to enhance our reconnaissance of the molecular inventory. The hope is, that with increasing sensitivity and completeness it will be possible to draw more general conclusions. When the overall run of molecular abundances is known, and the realizable abundances of DIB-carrier candidates are more tightly constrained, constraints on the line strength are implied, with consequences for the internal structure of putative carriers.

Wider searches for new molecular species in diffuse molecular gas are proliferating independent of considerations of the DIBs. One example is the recent 84-115 GHz spectral sweep from which Figure 1 and the three new detections reported here $\left(\mathrm{HCO}, c-\mathrm{C}_{3} \mathrm{H}\right.$ and $\mathrm{CF}^{+}$) were drawn; upper limits on the abundances of other species whose lower-lying transitions fall in the $3 \mathrm{~mm}$ band will follow from this sweep once some remaining lowlevel instrumental artifacts are removed. Projects such as the PRIMOS cm-wave spectral sweep of dense-gas emission toward Sgr B2 at the GBT (Zaleski et al. 2013) also observe absorption from intervening diffuse clouds, albeit in the central regions of the Galaxy.

Finally we note that the present chasm between microwave and optical spectroscopy of diffuse clouds, and any possible doubts about the relevance of microwave spectroscopy to the question of the DIBs, will disappear when large optical telesopes take spectra of the brighter radio-loud blazars such as BL Lac. Indeed it was hoped to present such spectra at this meeting, but BL Lac faded below 16th magnitude in the visible before the observations could be undertaken during the past observing season. Our hopes for this project, however, remain bright.

\section{Acknowledgements}

This work was funded in part by grant ANR-09-BLAN-0231-01 from the French Agence Nationale de la Recherche as part of the SCHISM project(http://schism.ens.fr/).

\section{References}

Cordiner, M. A. \& Sarre, P. J. 2007, A\& A, 472, 537

Federman, S. R., Strom, C. J., Lambert, D. L., Cardelli, J. A., Smith, V. V., \& Joseph, C. L. 1994, ApJ, 424, 772

Gerin, M., Kaźmierczak, M., Jastrzebska, M., Falgarone, E., Hily-Blant, P., Godard, B., \& de Luca, M. 2011, A\& A, 525, A116

Indriolo, N., Neufeld, D. A., Gerin, M., Geballe, T. R., Black, J. H., Menten, K. M., \& Goicoechea, J. R. 2012, ApJ, 758, 83

Liszt, H. \& Lucas, R. 2001, $A \mathscr{E} A, 370,576$

Liszt, H., Lucas, R., \& Pety, J. 2006, A\&A, 448, 253

Liszt, H., Sonnentrucker, P., Cordiner, M., \& Gerin, M. 2012, ApJ Letters, 753, L28

Liszt, H. S. 2012, $A \mathscr{E} A$, 538, A27

Liszt, H. S. \& Lucas, R. 1996, A\&A, 314, 917

-. 1998, A\&SA, 339, 561

Liszt, H. S. \& Pety, J. 2012, A\& $A$, 541, A58

Liszt, H. S., Pety, J., \& Lucas, R. 2010, A\&A, 518, A45

Lucas, R. \& Liszt, H. S. 1996, $A \mathscr{E} A$, 307, 237

-. 2000a, $A \& A, 358,1069$

-. 2000b, A\&A, 355, 327 
Maier, J. P., Chakrabarty, S., Mazzotti, F. J., Rice, C. A., Dietsche, R., Walker, G. A. H., \& Bohlender, D. A. 2011a, A\&A, 729, L20

Maier, J. P., Walker, G. A. H., Bohlender, D. A., Mazzotti, F. J., Raghunandan, R., Fulara, J., Garkusha, I., \& Nagy, A. 2011b, ApJ, 726, 41

Ohishi, M., Irvine, W., \& Kaifu, N. 1992, in Astrochemistry of cosmic phenomena: proceedings of the 150th Symposium of the International Astronomical Union, held at Campos do Jordao, Sao Paulo, Brazil, August 5-9, 1991. Dordrecht: Kluwer, ed. P. D. Singh, 171-172

Savage, B. D., Drake, J. F., Budich, W., \& Bohlin, R. C. 1977, ApJ, 216, 291

Schlegel, D. J., Finkbeiner, D. P., \& Davis, M. 1998, ApJ, 500, 525

Sheffer, Y., Rogers, M., Federman, S. R., Abel, N. P., Gredel, R., Lambert, D. L., \& Shaw, G. 2008, ApJ, 687, 1075

Smith, I. W. M., Herbst, E., \& Chang, Q. 2004, MNRAS, 350, 323

Snow, T. P. \& McCall, B. J. 2006, ARA\&A, 44, 367

Sonnentrucker, P., Welty, D. E., Thorburn, J. A., \& York, D. G. 2007, ApJ Supplement Series, 168,58

Tielens, A. G. G. M. 2010, The Physics and Chemistry of the Interstellar Medium (Cambridge University Press)

Turner, B. E., Herbst, E., \& Terzieva, R. 2000, ApJ Supplement Series, 126, 427

Weselak, T., Galazutdinov, G. A., Beletsky, Y., \& Krełowski, J. 2010, MNRAS, 402, 1991

Wilson, T. L., Rohlfs, K., \& Hüttemeister, S. 2009, Tools of Radio Astronomy (Springer-Verlag)

Yamada, K. M. T. \& Winnewisser, G. 2011, Interstellar Molecules, Springer Tracts in Modern Physics, 241

Zaleski, D. P., Seifert, N. A., Steber, A. L., Muckle, M. T., Loomis, R. A., Corby, J. F., Martinez, Jr., O., Crabtree, K. N., Jewell, P. R., Hollis, J. M., Lovas, F. J., Vasquez, D., Nyiramahirwe, J., Sciortino, N., Johnson, K., McCarthy, M. C., Remijan, A. J., \& Pate, B. H. 2013, ApJ Letters, 765, L10 